\title{
Importancia de los rituales de iniciación y de los tatuajes en las maras y pandillas centroamericanas
}

Stanisław Kosmynka

Universidad de Lodz, Polonia

Desde hace mucho tiempo, amplias zonas de América Latina se enfrentan a altos índices de criminalidad y violencia, incrementados por problemas de índole estructural, política y social, además de por las complejas condicionantes históricas de los países concretos de esta región del mundo. La actividad de grupos pequeños y organizados de delincuentes ha dado lugar, en muchos casos, sobre todo en las grandes aglomeraciones, a la cristalización de diversas formas de criminalidad, que constituyen a su vez uno de los factores desestabilizadores de la situación interna de estos países, lo cual quedaría perfectamente plasmado en el ejemplo de América Central.

La enorme escala del problema de la violencia delictiva en América Latina se ve atestiguada por el alto porcentaje de asesinatos en relación al número de habitantes, por las cifras inexorables que arrojan y por el hecho de que, en algunas zonas de esta parte del mundo, el nivel de violencia es paradójicamente más alto que en países afectados por conflictos armados de carácter interno. ${ }^{1} \mathrm{El}$ dinámico desarrollo del crimen organizado se ha correlacionado durante años con la actividad de los cárteles de la droga. ${ }^{2}$ Las especulaciones conectadas

\footnotetext{
1 Stelmach, 2017: 187.

2 Stelmach, 2017: 187.
} 
con el narcotráfico son protagonizadas por diferentes actores; unos de ellos son las pandillas centroamericanas, que en sus filas agrupan a las personas muy jóvenes, obtienen pingües beneficios del comercio de sustancias psicoactivas, además de llevar a cabo otras formas de acciones transgresoras, manteniendo a menudo una relación simbiótica con las redes transnacionales del crimen organizado. Su existencia vendría definida por una serie de interesantes mecanismos intragrupales que dicen mucho sobre la idiosincrasia de estos colectivos.

El objetivo de este artículo estriba en la caracterización de estos grupos sociales como subculturas neotribales de violencia, en cuyo funcionamiento desempeñarían un papel harto significativo los rituales de ingreso, las ceremonias de iniciación y todo un estrato simbólico, buena muestra de lo cual serían los tatuajes. Un elemento importante de este análisis es también la exposición de los vínculos existentes entre los rituales y las costumbres características de estos colectivos con el grado de adhesión a ellas y la identificación e identidad de sus miembros jóvenes. Las consideraciones aquí incluidas se centran en el ejemplo de los entornos que funcionan en muchas áreas de América Central y que son conocidos como La Mara Salvatrucha. Es menester subrayar que la metodología de la investigación sobre la delincuencia y sus aspectos sociales y psicológicos implica la necesidad de seleccionar una gama interdisciplinaria de métodos. A tenor de tales observaciones, la integración del método histórico ha resultado de gran utilidad, especialmente en cuanto a la aprehensión de la relaciones de causa y efecto en la cristalización de ciertos mecanismos, así como del método sistemático, que permite el tratamiento de los temas discutidos como un conjunto de elementos conectados entre sí, y cuyo foco se sitúa tanto en sus componentes constitutivos como en las relaciones mutuas, lo cual en este caso se aplica al cotejo y a la recopilación de determinadas prácticas y costumbres rituales celebradas por los grupos criminales antes mencionados.

La problemática de los mecanismos de formación y funcionamiento de las pandillas juveniles en Centroamérica ha sido analizada principalmente en el trabajo de autores latinoamericanos y norteamericanos, de entre los cuales podría mencionarse a Rebecca García Bravo, José Miguel Cruz, Juanjo Medina, Pedro Mateu-Gelabert, Juan José Sosa Melnedez, José Luis Rocha, Emilio Goubaud, Marlon Carranza, Clare Ribado Seelke, Michael Shifter. ${ }^{3}$ En el panorama polaco, el tema del crimen organizado y de las acciones emprendidas contra el mismo, tanto por las autoridades como por las organizaciones no estatales, se halla presente en las publicaciones de Michal Stelmach. ${ }^{4}$

\footnotetext{
3 Rebecca García Bravo 2013, José Miguel Cruz 2006, Juanjo Medina 2007, Pedro Mateu-Gelabert 2007, Juan José Sosa Melnedez 2001, José Luis Rocha 2001, Emilio Goubaud 2008, Marlon Carranza 2006, Clare Ribado Seelke 2009, Michael Shifter 2012.

${ }^{4}$ Stelmach 2017.
} 


\section{LA ESPECIFICIDAD DE LAS MARAS Y LAS PANDILLAS}

Los términos "maras" y "pandillas" se refieren a grupos de delincuencia urbana formados por jóvenes, nacidos hace varias décadas en los Estados Unidos, y cuyas filas se han nutrido principalmente de inmigrantes latinoamericanos para extenderse después a países de América Central, sobre todo a Guatemala, El Salvador y Honduras. Los términos "maras" y "pandillas" suelen aparecer como sinónimos en muchas definiciones. No está de más citar al respecto una de estas explicaciones: "las pandillas juveniles de carácter violento, más conocidas como maras, agrupaciones de jóvenes de ambos sexos, normalmente de edades comprendidas entre 5 y 35 años y que se unen con la autorización de controlar un barrio o territorio y que hacen de la pertenencia al grupo una forma de vida que los lleva a cometer cualquier tipo de delito e incluso perder la vida" ${ }^{5}$ En la segunda década del siglo XXI, se estimaba que en América Central había hasta 100,000 personas en las filas de estas organizaciones, rivales entre sí. ${ }^{6}$ Las bandas de este tipo más conocidas son La Mara Salvatrucha (MS-13) y Pandilla 18. Entre las principales razones de su cristalización, se encuentran varios factores correlacionados: pobreza y desempleo, desigualdades sociales, exclusión, acceso desigual a la educación y altas tasas de fracaso escolar, fácil acceso a las armas, etc. Estos elementos resultarían ser los catalizadores del desarrollo de grupos criminales en muchos países latinoamericanos.

Las maras y las pandillas definen, como se ya se ha mencionado, un tipo específico de entorno delictivo centroamericano, al cual suelen acceder jóvenes e incluso niños, ya que a menudo el proceso de influencia ejercido por las bandas comienza antes de cumplir los diez años, víctimas, en numerosos casos, de la marginación y la exclusión sociales y quienes, a la vez, buscan un sentido de pertenencia y comunidad. Es significativo que más del cincuenta por ciento de los niños y adolescentes reclutados en las filas de las maras hayan tenido una experiencia previa de consumo de sustancias psicoactivas, lo cual sin duda es uno de los factores que contribuye a la adhesión a entornos criminales. ${ }^{7}$ Vivir al ritmo de estas subculturas específicas, cuyo funcionamiento está determinado por un sistema axionormativo interno y propio, constituye para estos individuos un sustituto de la familia, e incluso se vuelve más importante que ella misma, puesto que les proporciona un propósito y un significado a sus vidas. Y también satisface, en buena medida, importantes necesidades de identidad. ${ }^{8}$ Por lo tanto, cabe acentuar que, en un sentido sociológico, el establecer el grupo primario,

\footnotetext{
5 García Bravo, 2013: 12.

${ }^{6}$ Munaiz 2014.

7 BAKRANIA 2013: 9.

${ }^{8}$ Winton 2012: 142-143.
} 
las maras, y el participar en ellas goza de un significado que va más allá de las meras ganancias económicas resultantes de la ejecución de actividades delictivas. ${ }^{9}$ Para muchos jóvenes, estos grupos cumplen una misión identificativa y, a la par, con un importante carácter afectivo.

Aun cuando estas organizaciones difieren en algunos aspectos, Rebeca García Bravo enumera varios rasgos comunes a los grupos criminales conocidos como maras o pandillas juveniles violentas:

- "Ingreso a través de procesos de iniciación;

- comisión de delitos mayores como forma habitual de actuación, tales como homicidios, atracos, robos, secuestros o tráfico de drogas;

- vínculos con crimen organizado; elevado número de integrantes;

- tatuajes como medio de expresión y distinción;

- uso indiscriminado de la violencia;

- estado de guerra permanente con otras pandillas;

- ocupación de un determinado sector territorial;

- imposición sobre población más indefensa mediante el terror;

- la obediencia implícita del miembro hacia el líder;

- pertenencia al grupo de por vida, castigándose la salida no autorizada con la muerte". ${ }^{10}$

Es necesario subrayar que, aunque estos determinantes indican algunas características distintivas generales, estos colectivos suelen ser heterogéneos y diversos. Por ejemplo, en el seno de la Mara Salvatrucha, existen grupos autónomos y territoriales con símbolos similares y afiliados bajo un nombre común. ${ }^{11}$ Curiosamente, podría establecerse aquí cierta analogía con las células terroristas yihadistas, cuyo funcionamiento también se asemeja a la estructura de una red, cohesionada por un determinado componente ideológico y cimentada por lazos sociales cercanos y directos de parentesco o amistad (pandilla de amigos), acerca de lo cual ha escrito uno de los expertos en el tema, Marc Sageman. ${ }^{12}$ De forma semejante al caso de las células terroristas, gozan de gran importancia el rigor en los mecanismos de control interno del grupo, las normas y las sanciones, que obligan a sus miembros a un grado de conformismo de enorme alcance.

\footnotetext{
9 Goubaud 2008: 36.

10 García Bravo 2013: 13.

11 Stelamch 2017: 192.

12 Segeman 2008: 29-31.
} 


\section{RituALES DE INICIACIÓN}

Como ya se ha dicho, los rituales y prácticas de iniciación ejercen un papel crucial en las pandillas delictivas centroamericanas. Les confieren una dimensión especial de pertenencia al grupo y sirven para demostrar su carácter exclusivo. Además, componen una especie de rito de iniciación, una suerte de "prueba de fuego" que verifica el acceso a sus estructuras y separa simbólicamente al miembro de la pandilla recién admitido de las primeras etapas de su vida. Debe hacerse hincapié en que, en este caso, el cultivo de costumbres y tradiciones específicas está fuertemente entrelazado con el cambio hacia otro estatus social, además de establecer también un límite formal entre el individuo perteneciente al grupo y todos los demás, situados fuera de él. ${ }^{13}$ No obstante, por lo que atañe a las maras y pandillas, dichas prácticas no deben verse como idénticas e iguales; pueden presentar aspectos muy diversos. Los ejemplos dados a continuación ilustran su particularidad y destacan algunos de sus mecanismos típicos y repetitivos. Con todo, debe advertirse que no cada candidato a miembro de estas estructuras está sujeto a ritos de iniciación; en este aspecto, se observan diferencias entre pandillas concretas de América Central, e incluso según las ciudades en las que operan. Juanjo Medina y Pedro Mateu-Gelabert señalan que, a menudo, el papel más importante en la formación de vínculos lo ostentan las interacciones cercanas y primarias entre conocidos y amigos de un distrito determinado. ${ }^{14} \mathrm{~A}$ su vez, las prácticas de ingreso y este simbolismo privativo ayudan a crear un aura de romanticismo, exclusividad y misterio, que, especialmente para los jóvenes, constituye un valor adicional atractivo y resulta ser un factor vinculante para el grupo. ${ }^{15}$ Por ejemplo, según los datos de la primera década del siglo XXI, se celebraron rituales de entrada para los miembros de la Mara Salvatrucha en El Salvador en un 72 por ciento aproximadamente. También se celebraron en Guatemala: hasta en un 25 por ciento, mientras que en Honduras también se llevaron a cabo para los miembros de la Pandilla 18, en un 52 por ciento más o menos. ${ }^{16}$

Recordemos a la sazón cómo el antropólogo Max Gluckman ha argumentado que el rito de iniciación es típico de las comunidades tribales, pero que desaparece en las sociedades industriales, donde los lazos sociales se debilitan y es la individualidad la que adquiere importancia. ${ }^{17}$ En estas sociedades los ritos pierden sus raíces y significación y presentan un perfil lúdico. Teniendo en

\footnotetext{
13 Gluckman 2012; 250-251; van Genner 2006.

14 Medina, Mateu-Gelabert 2007: XXVIII.

15 Medina, Mateu-Gelabert 2007: XXVIII.

16 Medina, Mateu-Gelabert 2007: XXVII.

17 GlucKman 2012: 250-251.
} 
cuenta este concepto, la presencia de rituales de iniciación en subculturas criminales puede considerarse como un reflejo de su carácter neotribal, donde el territorio y su defensa ocupados por otros grupos antagónicos adquieren un significado especial, esto es, la necesidad de definirse simbólicamente en cuanto a la separación de otras comunidades, de demarcar la frontera entre "lo propio" y "lo ajeno", así como de guardar una ceremonia de unión para con el grupo de "iniciados". Las prácticas de tránsito son un determinante en la creación de roles sociales y, al mismo tiempo, cumplen una importante función integradora y diferenciadora. ${ }^{18}$

Cabe señalar que estos ritos se producen en ambientes, donde el sufrimiento físico, la violencia, el sacrificio y el sometimiento disfrutan de elevada significación. Por ejemplo, si una mujer desea ingresar en la Mara Salvatrucha, suele esperarse de ella que mantenga relaciones sexuales con todos o algunos de los hombres pertenecientes a una pandilla determinada. ${ }^{19}$ En este contexto, las interacciones con los hombres están marcadas por patrones patriarcales, basados en los indicadores de machismo típicos de la cultura tradicional mestiza ${ }^{20}$ y consistentes en la subordinación y la sumisión femeninas. Estas costumbres y normas sociales han implicado, desde siempre, la aceptación de castigos impuestos a la mujer por su desobediencia o infidelidad y han ejercido igualmente un control sobre su sexualidad y otros aspectos de la vida. En muchos casos, por ejemplo, en las pandillas existentes en Honduras, solo se aceptan relaciones endogámicas, es decir, entre las mujeres pertenecientes a estos grupos y los hombres miembros de los mismos.

Sería pertinente añadir que inicialmente las mujeres no fueron admitidas en los entornos delictivos, pero con el paso del tiempo y la diversificación de sus formas de actividad, esta situación ha ido cambiando. Según una investigación de la segunda mitad de la primera década del siglo XXI, las mujeres constituirían alrededor de un cuarenta por ciento de la totalidad de los miembros de las Maras, ${ }^{21}$ pero serían los hombres quienes desempeñarían las funciones sociales más importantes en estos colectivos, siendo sus líderes y sus "soldados". Las mujeres miembros de los grupos criminales están sujetas a la dominación masculina y ejecutan las tareas asignadas tradicionalmente a su género, aunque no faltan casos, incluso no son insólitos, de su participación activa en contravenciones a la ley, especialmente en lo concerniente al tráfico de sustancias psicoactivas.

\footnotetext{
18 Buchowski 1985: 66.

19 Goubaud 2008: 39.

20 ŚNIADECKA-KOTARSKA 2003: 68-70.

${ }^{21}$ Medina, Mateu-Gelabert 2007: XXVI.
} 
Un candidato a miembro de las pandillas (la Mara Salvatrucha, Pandilla 75, Pandilla 18) es, por lo general, introducido en el ambiente por otros miembros del grupo quienes suelen presentar sus recomendaciones a favor de su admisión. A veces, al iniciado se le somete a una prueba a fin de comprobar su predisposición física y psicológica para pertenecer a la organización. Las formas y tipo de dichas pruebas difieren de un grupo a otro, pero su denominador común es un tanteo que verifique el nivel de coraje y resistencia al dolor físico. ${ }^{22}$ Una de las estrategias de iniciación más comunes es la de someter al novato a una agresión física, que implique golpes de otros pandilleros (la llamada brincadera, ritual marero) o la exigencia de que participe en una pelea con personas que pertenecen a un grupo criminal rival. En la primera variante de este rito, el iniciado debe entregarse voluntariamente a una sarta de golpes de varios segundos de duración y encajarlos sin mostrar miedo. ${ }^{23}$ Esta práctica está relacionada con la elaboración y el funcionamiento específicos de una imagen del hombre como un macho resistente al dolor, sin temor alguno al sufrimiento, y cuyas cicatrices y secuelas resultantes de la agresión darán testimonio simbólico de su coraje y masculinidad, virtudes especialmente valoradas en colectivos, para los que la lucha y la agresión física se han convertido en componentes inmanentes de su existencia.

Añadamos que también se da el caso cuando, para "merecer" la admisión a este colectivo, al aspirante se le obliga a introducirse en un área controlada por un grupo criminal rival, con el objetivo de acabar con la vida de uno de sus representantes. Otra tarea bastante común, que se le suele encomendar al candidato, es la de robar o desvalijar. Esta clase de acciones coercitivas vienen a revelar conexiones con rituales de transición establecidos por muchas comunidades indígenas en varias partes del mundo, consistentes en realizar actos que requieran valentía y cuya ejecución conlleve el riesgo de perder la vida: por ejemplo, derrotar y matar a un depredador o guerrero que pertenece a una tribu enemiga. Sólo tras haber sido ejecutada una de estas acciones, el niño es reconocido por la comunidad como un hombre. Según todo lo dicho, se hace muy importante resaltar que unirse al grupo significa al mismo tiempo someterse a su influencia y acatar sus reglas y hábitos; a su vez, la aceptación y experiencia de las ceremonias son, como se ha mencionado, un gesto de subordinación a las normas del grupo y a sus líderes. ${ }^{24}$ La severidad del control social es un determinante en extremo importante en la formación de lazos humanos, pues estos son los que consolidan las filas de este tipo de comunidad. En muchos casos, sin embargo, estas no son las únicas prácticas: a veces se exige de

22 García Bravo 2013: 15; Goubaud 2008: 38.

${ }^{23}$ Ribando SeElKe 2009: 17.

${ }^{24}$ García Bravo 2013: 67. 
los candidatos a las pandillas que se sometan a un período de prueba durante el cual se verifica la lealtad de los principiantes, se espera el cumplimiento de ciertos cometidos, se comprueban las predisposiciones, etc. Así, por ejemplo, según estudios realizados en la primera década del siglo XXI, en la Mara Salvatrucha, este período abarcó siete meses en Guatemala, dos en El Salvador y uno en Honduras, mientras que en Pandilla 18, que opera en los mismos países, fue de dos meses. ${ }^{25}$

\section{SigNifiCADO DE LOS TATUAJES}

Los tatuajes también cumplen una significación simbólica para los miembros de la Mara Salvatrucha y para muchos otros grupos criminales. Como ya es sabido de todos, la práctica de decorar el cuerpo mediante la introducción de un tinte orgánico en la piel, que presenta sus propias condiciones culturales asociadas con las creencias locales y los rituales específicos de un pueblo o tribu, se da en todos los continentes. ${ }^{26}$ En muchas sociedades, los tatuajes tenían una función espiritual o mística; asimismo, se convirtieron en emblemas de colectivos en conflicto con la ley, marginales o de índole subversiva. Valgan como ejemplo los tatuajes característicos de los miembros de la mafia rusa ${ }^{27} \mathrm{u}$ otras organizaciones criminales, que se realizaban tanto en el pasado, como se realizan en el presente.

Por lo que respecta a los representantes de las subculturas criminales de América Central, los tatuajes desempeñan un papel distintivo especial, y esto no solo cuando se trata de presos o de excarcelarios. A menudo cubren la mayor parte del cuerpo de los individuos, sirviendo, por ende, de mensaje social a través del cual se informa sobre su integración en un grupo determinado. Presentan un carácter de estigma voluntario que se ha autoimpuesto el miembro de la pandilla; un estigma que se erige a la vez en motivo de orgullo y en advertencia para todos los que lo vean. No es raro que incluso el rostro se halle cubierto de tatuajes, aunque esto generalmente se hace entre las personas encarceladas, porque de lo contrario permitiría fácilmente que las autoridades policiales o los miembros de un grupo rival lo eliminaran. Curiosamente, algunos de esos tatuajes son de índole religiosa, otros contienen información concreta, por ejemplo, sobre el número de personas asesinadas, o comunican la pertenencia a un grupo en particular. ${ }^{28}$ Además del negro, los colores más comunes son el ver-

\footnotetext{
25 Medina, Mateu-Gelabert 2007: 32.

26 JASEK, KostUlSKi, GMitrowicz 2011: 225.

27 Galeotti 2020; VARESE 2009: 221-226.

${ }^{28}$ Khromina 2007: 96-97.
} 
de y el azul. Generalmente, los tatuajes son realizados por otros miembros del grupo; por otra parte, el hecho de que se requiera la aprobación previa de su líder en cuanto a los motivos y a los modelos de los mismos, pone una vez más de manifiesto la naturaleza jerárquica de estas sociedades. Ejemplos de ello serían las normas internas que rigen la vida de las pandillas de Guatemala, El Salvador y Honduras. Los tatuajes constituyen un registro simbólico de los actos de una persona, como si fueran/constituyeran una biografía visual de las personas que integran una determinada subcultura criminal. ${ }^{29}$

Según el experto en tráfico de drogas y crimen organizado, David Martínez-Amador, "hoy, en la subcultura criminal del mundo de las pandillas, los tatuajes tienen un significado diferente. Son un signo de tinta del contrato firmado con el gran Leviatán, con el Leviatán «la vida loca»" ${ }^{30}$ El tatuaje suele contener datos sobre la posición ocupada por el sujeto en el seno de su grupo, así como sobre los actos delictivos que ha perpetrado. Veamos algunos de los símbolos de uso frecuente, tatuados en diferentes partes del cuerpo, incluidos los rostros de los jóvenes pertenecientes a varias maras y pandillas: ${ }^{31}$

- Letras "MS", abreviatura de Mara Salvatrucha.

- Número 18, que significa Pandilla 18.

- Lágrimas. Pueden significar tristeza por las transgresiones perpetradas o por la pérdida de amigos de la pandilla asesinados. Son propias de los encarcelados en centros penitenciarios y simbolizan el anhelo de la libertad perdida. Las lágrimas negras hablan de que la persona marcada por este tatuaje ha cometido un asesinato.

- Manos juntas en oración. Se refieren al presunto arrepentimiento de la persona por haberse entregado a acciones malvadas;

- Telaraña. Por lo general, se lleva dibujada sobre los hombros y simboliza los vínculos entre los grupos y la fuerza abarcada, así como la imposibilidad de zafarse de la pertenencia al grupo. Igualmente puede significar adicción a sustancias psicoactivas.

- La letra N, que significa Norte y sugiere el origen "ennoblecido" del portador del tatuaje (La Mara Salvatrucha surgió, según se ha mencionado, en el territorio de los Estados Unidos y, por lo tanto, en el Norte).

- Sombrero, arma, calavera. Estos símbolos se refieren a las imágenes de la revolución de principios del siglo XX, profundamente arraigadas en el ideario colectivo del pueblo mexicano, y dan a entender que el portador lucha contra el "sistema"; es un ícono de un luchador

\footnotetext{
${ }^{29}$ Medina, Mateu-Gelabert 2007: 30.

30 Munaiz 2014.

31 Munaiz 2014; SCHIFTER 2012: 10-11.
} 
revolucionario, que sacrifica su vida por la causa por la cual se está luchando.

- Perro bulldog. Significa el vínculo fraternal existente dentro del grupo original, que es la pandilla de amigos. Este motivo suele aparecer sobre todo en los tatuajes de los chicanos adheridos a pandillas activas en California, en el área de Fresno.

- Letras MM, que son las siglas de "La Mexican Mafia".

- Las cruces indican miembros de una mara determinada asesinados.

- Lápida. Informa sobre las lesiones sufridas durante la lucha.

- Mujeres desnudas. Sugieren las conexiones de la pandilla con las ganancias extraídas de la prostitución y el proxenetismo.

- Los signos satánicos constituyen una advertencia a los enemigos de que la persona con este tatuaje es un guerrero.

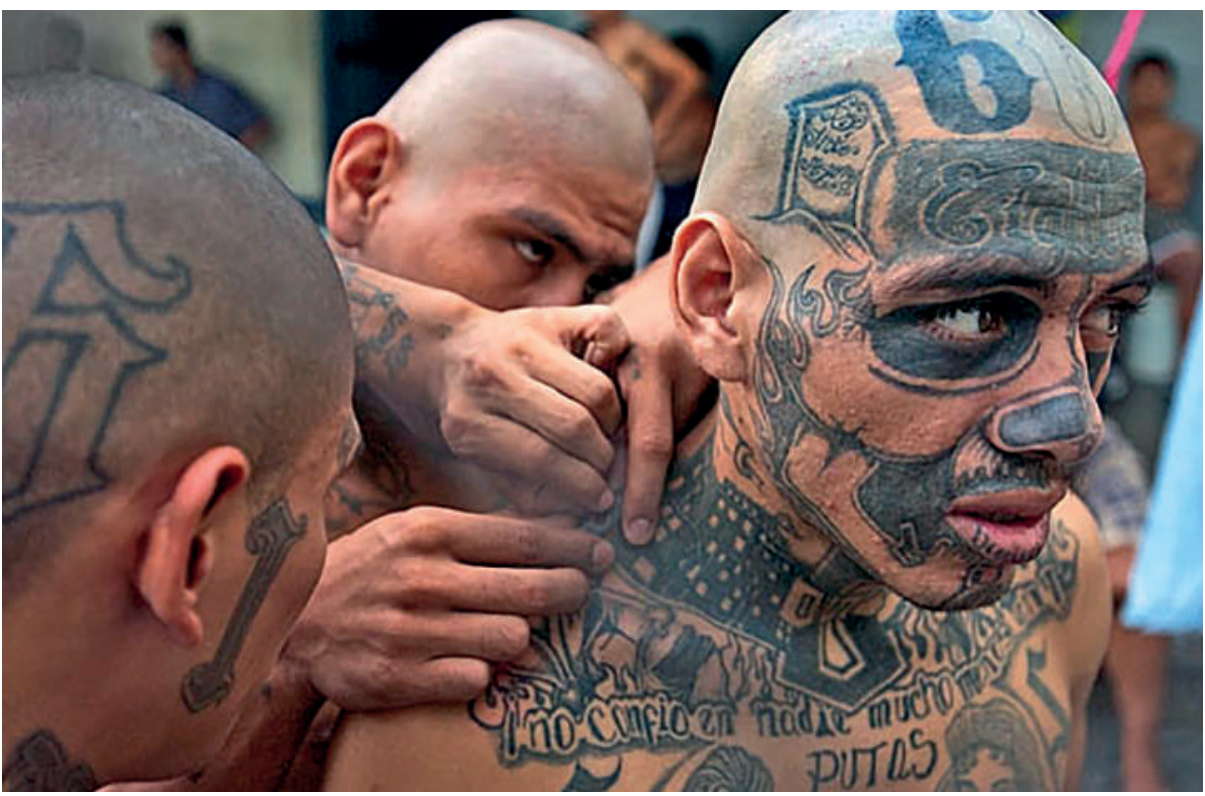

Fig. 1. Los tatuajes de los Mara Salvatrucha, fot. Victor J. Blue, (http://tatuajex. com/1907/los-tatuajes-de-los-mara-salvatrucha [11.05.2020]). 

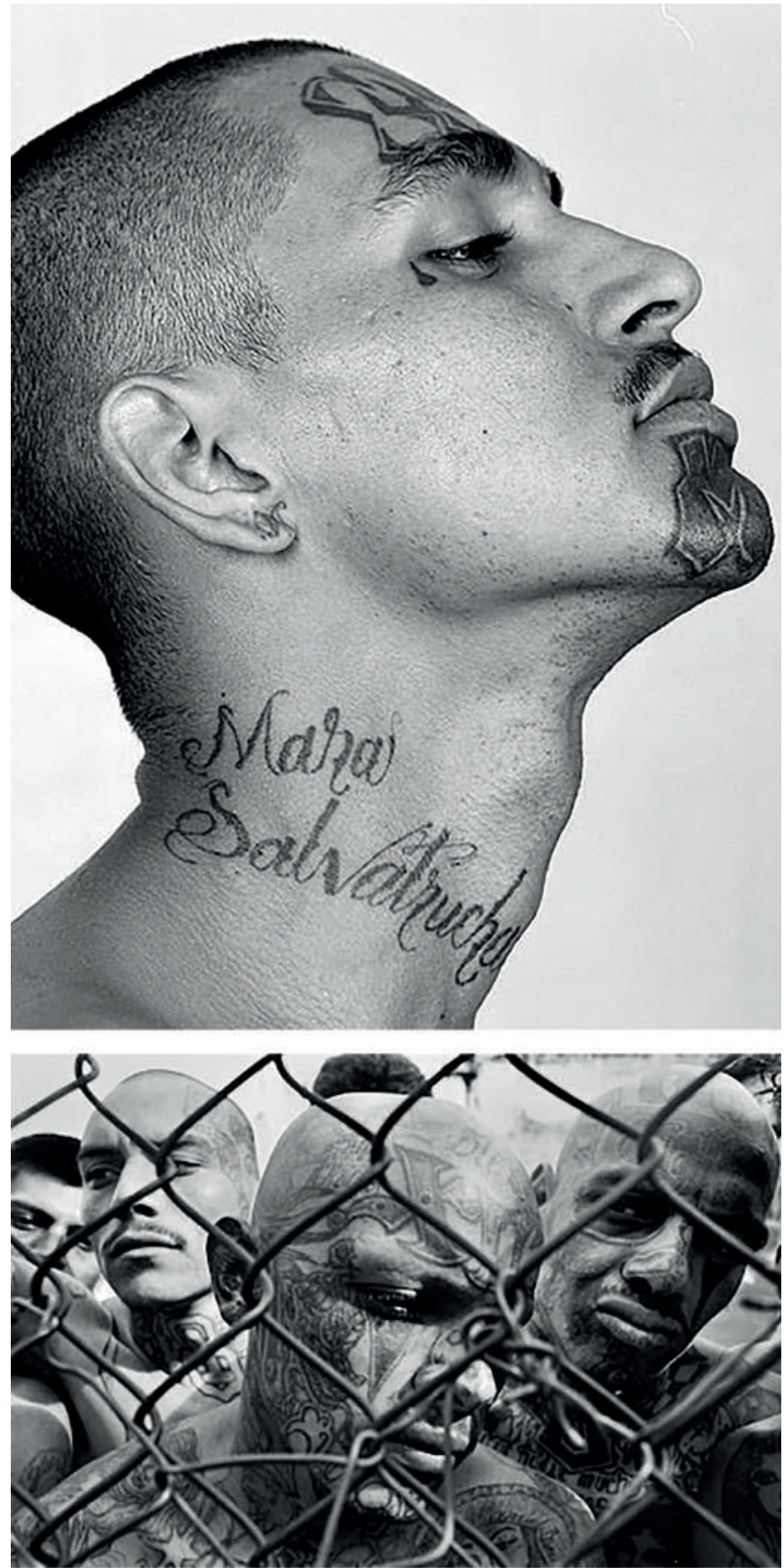

Fig. 2. Tatuaje de la Mara Salvatrucha, fot. Cristian Poveda (https://www.vallekastattoozone.es/las-maras-y-los-tatuajes/ [11.05.2020]). 


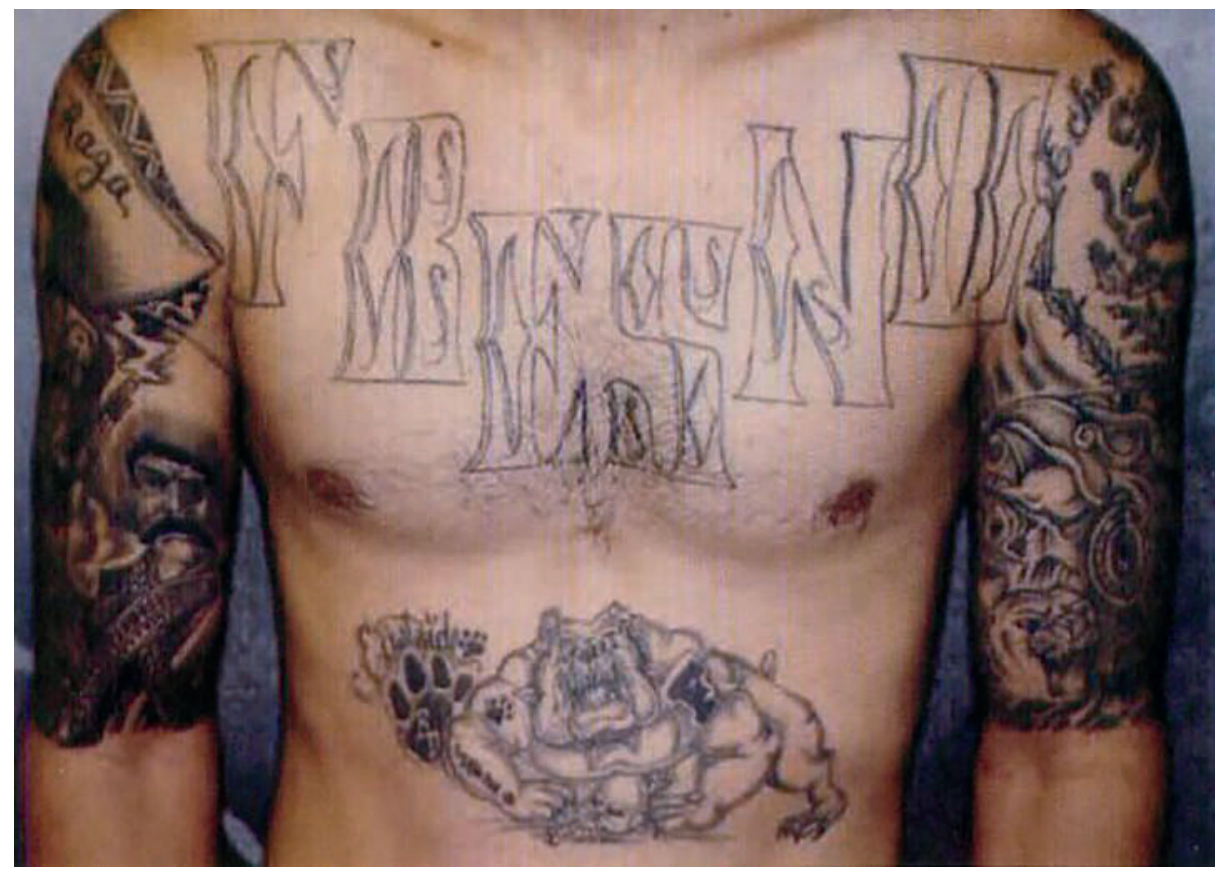

Fig. 3. El perro buldog, tatuaje de la área de Fresno, California (https://elpais.com/internacional/2014/04/04/actualidad/1396576833_271822.html [11.05.2020])

Por supuesto, estos son tan solo una selección de los símbolos que suelen aparecer en los tatuajes de las maras. Como se mencionó anteriormente, estas imágenes presentan motivos que determinan la pertenencia a un grupo criminal dado y que expresan el coraje y la brutalidad de los actos de los jóvenes, así como su manifiesta actitud de nonchalance y su despreocupación frente a la vida y la muerte.

Debe asimismo recordarse el hecho de que llevar el cuerpo tatuado se convierte a menudo en una razón suficiente para detener a jóvenes por parte de las autoridades policiales y someterlos después a medidas represivas, lo cual ha sido señalado reiteradamente, a través de una serie de informes, por las organizaciones no gubernamentales que monitorean los casos de violaciones de derechos humanos en América Central. ${ }^{32}$ Estos casos reflejan la convicción errónea de que un endurecimiento de las penas resultaría ser la panacea para el problema del crimen menor y organizado. La expansión de los medios represivos no ha sido más que la consecuencia de la estrategia de "mano dura", empleada por muchos gobiernos de la región en su lucha contra la delincuencia organizada,

${ }^{32}$ Carranza 2006: 241. 
y que, debido a su carácter selectivo, a las altas tasas de corrupción y de connivencia en actividades criminales de los funcionarios encargados de hacer cumplir la ley y a la disfuncionalidad del Estado, visible en tantas áreas, es difícil considerarla como efectiva.

En los esfuerzos por neutralizar las amenazas de los grupos criminales, es obvio que los tatuajes han pasado a ser un elemento importante, dada la posibilidad de reconocer a los individuos adheridos a dichos círculos. De la evidente importancia de este simbolismo dan cuenta las regulaciones legales implementadas en esta región, por las cuales se considera la aparición de tatuajes como un elemento capaz de permitir la identificación de un miembro afiliado a un grupo criminal. Un buen ejemplo de esto sería la llamada "Ley Antimaras" adoptada en 2003 en El Salvador, que permitía el reconocimiento de los miembros de estas organizaciones, como personas que llevan a cabo actos de infracción contra la ley, que ocupan un territorio concreto, que mantienen reuniones periódicas y que subrayan con mayor ahínco su identidad y pertenencia por medio de cicatrices y tatuajes (Artículo 1). ${ }^{33}$ Es por eso que en los últimos años muchos miembros de las maras han comenzado a usar tatuajes en las partes del cuerpo cubiertas, por lo general, con ropa, incluso en las partes más íntimas, o que hasta han abandonado este uso ante tamaños de efectos estigmatizantes. ${ }^{34}$

José Sosa Meléndez y José Luis Rocha abordan el tema del tatuaje desde el punto de vista de otra de sus funciones, por cierto, no menos importante. No son fácilmente borrables y quedan indeleblemente marcados en el usuario, lo que hace que la posibilidad de abandonar una subcultura criminal sea muy remota. ${ }^{35}$ En numerosos casos, el intento de salir de la organización es considerado como traición y severamente castigado, incluso con la muerte. Los tatuajes testimonian de la autoidentificación con una estructura criminal dada; incluso en la posibilidad remota de que se pudiera abandonarla con éxito, el sujeto siempre sería automáticamente identificado por el entorno como un acólito de las maras o las pandillas, de lo que se derivarían para él las consabidas consecuencias. En este sentido, los tatuajes designan, de alguna manera, las identidades de los individuos dentro de este colectivo, inscribiéndose en el esquema de los llamados "grupos voraces", capaces de absorber por completo a sus miembros, tal y como lo concibe el sociólogo estadounidense Louis Coser. ${ }^{36}$

Los tatuajes, como ya se ha dicho, constituyen un elemento visual distintivo, que le lanzan a la sociedad un tipo de mensaje propio. Resulta significativo que vaya acompañado por otros canales de comunicación de naturaleza

\footnotetext{
33 SANTAMARÍA 2013: 74.

34 García Bravo 2013: 17; Santamaría 2013: 75.

35 Sosa MeléndeZ, Rocha 2001: 384-385.

${ }^{36}$ Coser 1974.
} 
simbólica, como grafiti, lemas escritos en las paredes, jerga especial, ropa y gestos, generalmente con connotaciones informativas, que incluyen amenaza, aviso, designación de territorio, etc. Estos últimos también presentan un carácter simbólico y cumplen una función identitaria. Los tatuajes, como una forma particular de acicalarse y jactarse, expresan un estilo característico de un grupo dado y un metalenguaje decodificado por los miembros de dicho grupo. Cabe subrayar que la dimensión del impacto social es un elemento importante en el funcionamiento de las maras y las pandillas y que no solo va destinado a los grupos antagónicos y a las autoridades, sino que también cumple un objetivo en cuanto a la socialización de los adolescentes en cuanto a su futuro papel como delincuentes y en cuanto a la satisfacción de sus necesidades identitarias.

En resumen, todas las prácticas y rituales detallados más arriba, además de sus funciones distintivas y alegóricas, confieren un aura de elitismo y de carácter cuasi religioso a las comunidades en las que se practican. Les proporcionan a sus miembros una sensación de singularidad y consolidan esta comunidad. Es significativo que en los últimos años se estén desarrollando programas, cuyo objetivo es la resocialización y la reinserción sociales de los ex miembros de las maras, en los que la desmitificación de las prácticas de formación de vínculos y la puesta en evidencia de su auténtica naturaleza desempeñan un papel importante. Ejemplo de esto serían las actividades realizadas por las ONG en El Salvador, que incluyen acciones para eliminar emblemas visuales, es decir, pertenecientes a subculturas criminales (por ejemplo, el proyecto "Adiós Tatuajes"). ${ }^{37}$ Dada la disfuncionalidad de muchos países centroamericanos y la ineficacia de su política de "mano dura", pareciera que el desarrollo de medidas preventivas "blandas" debería ser un elemento importante y algo complementario para el aparato de la ley en las acciones destinadas a neutralizar la criminalidad. Entre otros, cabría destacar la mejora de las condiciones para el cumplimiento de la pena en los establecimientos penitenciarios, así como la puesta en marcha de mecanismos para supervisar a los presos, el desarrollo de programas de inclusión social, tanto para expresos como para otras personas que son vistas como particularmente vulnerables al impacto de las bandas criminales.

Sin embargo, no puede ignorarse cuán difíciles de llevar a cabo son tales postulados, si se tienen en cuenta las altas tasas de pobreza y de exclusión social, la falta de presencia real del estado en algunos distritos o regiones, los casos de abuso y violencia por parte de los organismos encargados de hacer cumplir la ley, etc. En algunos estudios, incluso se habla de la existencia de un "vacío estado" (vacíos estatales) (Figuerola Ibarra, 2005: 2003-2006), entendido este como el conjunto de deficiencias institucionales y de falta del ejercicio

37 Aguilar, Miranda 2006: 66, 83-100. 
por parte de las autoridades, tanto a nivel local como central, de una serie de funciones, entre otras, en el campo de las garantías de la seguridad, del acceso a la educación, de la atención médica, etc. La resocialización de los ex miembros de las maras y la prevención de la influencia y captación de miembros por parte de estas organizaciones resultan procesos difíciles de implementar, puesto que significa imponerles una ruptura de vínculos con un colectivo que les satisface necesidades emocionales importantes. La vida de muchos mareros es breve; se ve truncada a resultas de enfrentamientos con otras bandas o con la policía, sin olvidarnos del consumo de drogas que también contribuye a ello en buena media.

Sin embargo, esta realidad no desalienta a otros candidatos a miembros de estas subculturas, deseosos de adherirse a sus filas y empujados por los problemas estructurales, ya indicados anteriormente, a los que enfrentan varios países latinoamericanos. Debe tenerse en cuenta que un serio obstáculo para nivelar el impacto de estos entornos lo constituye también la escasez de programas y de proyectos de ayuda estatal y la estigmatización social que afecta a los "niños de la calle". A tenor de esta situación, en muchas regiones de América Latina, se observa ya desde hace años un proceso de privatización del sector de la seguridad, en el que las agencias de seguridad privada, accesibles solo para las capas sociales acomodadas, han cobrado especial importancia.

Ante la falta de superación de tales desafíos, no es de extrañar que, para muchos jóvenes, sumidos en las dificultades en su existencia diaria y en la falta de perspectivas, la oferta que les dirigen las organizaciones criminales les resulte atractiva. Estos procesos siguen siendo motor de creación de importantes retos con respecto a la seguridad, que derivan de la captación de jóvenes llevada a cabo por parte de grupos criminales, constituidos como subculturas neotribales peculiares y en posesión de rituales propios y de prácticas de iniciación, de códigos de lenguaje y de atributos simbólicos de pertenencia. 


\section{BibLIOGRAFíA}

Aguilar, Lissette 2006 - Jeanette Aguilar, Miranda Lissette, Entre la articulación y la competencia: las respeustas de la sociedad civil organizada a las pandillas en el Salvador, en: J. M. Cruz (eds.), Maras y pandillas en Centroamérica. Las respuestas de la sociedad civil organizada, Vol. IV, UCA Editores, El Salvador, 2006, pp. 37-143.

BAKRANIA 2013 - Shivit Bakrania, Policy responses to criminal violence in Latin America and the Caribbean, GSDRC Report, 24.04.2013.

Buchowski 1985 - Michał Buchowski, Etnologiczna interpretacja obrzędów przejścia, „Lud”, t. 69 (1985), pp. 63-73.

CARRANZa 2006 - Marlon Carranza, Del asistencialismo a la incidencia y el cabildeo: las diversas respuestas de la sociedad civil organizada al fenómeno de las pandillas, en: Honduras. En: J.M. Cruz (eds.), Maras y pandillas en Centroamérica. Las respuestas de la sociedad civil organizada, Vol. IV, El Salvador: UCA Editores, 2006, pp. 235-328.

COSER 1974 - Lewis Coser, Greedy Institutions: Patterns of Undivided Commitment, New York: Free Press, 1974.

Galeotti 2020 - Mark Galeotti, Wory. Tajemnice rosyjskiej supermafi, trad. P. Cichawa, Warszawa: Znak, 2020.

García Bravo 2013 - Rebeca García Bravo, Maras en Centroamérica y en México (Costa Rica, Guatemala, Honduras, Nicaragua, Panamá, El Salvador), Madrid: Comisión Española de Ayuda al Refugiado, 2013.

Gluckman 2012 - Max Gluckman, Politics, Law and Rituals in Tribal Society, New York: Transaction Publisher, 2012.

Goubaud 2008 - Emilio Goubaud, Maras y pandillas en Centroamérica, "Urvio. Revista Latinoamericana de Seguridad Ciudadana", no. 4, mayo (2008), pp. 35-46.

Figuerola IbarRa 2005 - Carlos Figuerola Ibarra, Nuevos odres y viejos vinos: la violencia en América Latina en los albores del siglo XXI, en: Poder y política en América Latina, T. Castro Escudero, L. O. Costilla (eds.), "El Debate Latinoamericano", vol. 3, Buenos Aires: Siglo Veintiuno Editores, 2005, pp. 186-213.

JASEK, Kostulski, Gmitrowicz 2011 - Arkadiusz Jasek, Adrian Kostulski y Agnieszka Gmitrowicz, Analiza samookaleczeń i tatuowania w grupie osób prezentujacych obie cechy, "Psychiatria Psychologii Klinicznej", 11 (4) (2011), pp. 224-231.

Khromina 2007 - Sylvia Khromina, The Broken Path: Juvenile Violence and Delinquency in Light of Sociological Theories, "Human Architecture: 
Journal of the Sociology of Self-Konwledge", vol. 5, issue 2 (2007), pp. 91-100.

Medina, Mateu-Gelabert 2007 - José Medina y Pedro Mateu-Gelabert, Maras y pandillas, comunidad y policía en Centroamérica. Hallazgos de un estudio integral, (octubre de 2007), DEMOSCOPÍA S.A.

MunaIz 2013 - Claudia Munaiz, La Mara: un lienzo de vida y muerte en la piel, (10 de abril de 2013), „Internacional”.

Ribando Seelke 2009 - Clare Ribando Seelke, Gangs in Central America, "Congressional Research Service", (December 4, 2009), CRS Report for Congress.

Sageman 2008 - Marc Sageman, Leaderless Jihad. Terror Networks in the Twenty-First Century, Philadelphia: University of Pennsylvania Press, 2008.

SANTAMARÍA 2013 - Gema Santamaría, La difusión y contención del crimen organizado en la subregión México-Centroamérica, en: J. C. Garzón, E. L. Olson (eds.), La diáspora criminal: la difusión transnacional del Crimen Organizado y cómo contener su expansión, Washington: Wilson Center, 2013, pp. 59-100.

SHIFTer 2012 - Michael Shifter, Countering Criminal Violence in Central America, Council on Foreign Relations. Center for Preventive Action, Council Special Report No. 64, (April 2012), pp. 5-72.

Sosa Meléndez, Rocha 2001 - Juan José Sosa Meléndez y José Luis Rocha, Las pandillas en Nicaragua, en: Maras y pandillas en Centroaméri$c a$, Managua: UCA Publicaciones, 2001.

Stelmach 2017 - Michał Stelmach, Bezpieczeństwo w Ameryce Środkowej w XXI w. Między terroryzmem kryminalnym a terrorem państwowym, en: T. Domański (ed.), Międzynarodowe oblicza terroryzmu. Ujęcie interdyscyplinarne, Łódź: Wydawnictwo Uniwersytetu Łódzkiego, 2017, pp. 185-207

ŚniAdeCKA-KotARSKa 2003 - Magdalena Śniadecka-Kotarska, Być kobieta w Ekwadorze, Warszawa: CESLA, 2003.

VAN GENNEP 2006 - Arnold van Gennep, Obrzędy przejścia, Warszawa: PIW, 2006.

VARESE 2009 - Federico Varese, Mafia rosyjska: prywatna ochrona $w$ nowej gospodarce rynkowej, trad. A. Gąsior-Niemiec, Warszawa: Oficyna Naukowa, 2009.

Winton 2012 - Ailsa Winton, Analysing the geographies of the 'transnational' gangs of Central America: the changing space of violence, "Investigaciones Geográficas", Boletín del Instituto de Geografía, núm. 79 (2012), pp. 136-149. 


\section{Summary}

Importance of initiation rituals and tattoos in Central American "maras" and "pandillas"

The main purpose of the paper is to analyse the phenomenon of the identity of some criminal gangs in Central America (maras y pandillas). It shows mechanisms and symbolic aspects of their activities in this region, especially in Guatemala, Salvador and Honduras, exemplified by a group called la Mara Salvatrucha. The article presents the cultural and social background of these criminal communities involved in many illegal activities and the multidimensional problem of violence. The paper is focussed on the identity of the members of the criminal gangs analysed as the subcultures of violence and as a kind of contemporary urban tribes. It shows the most important symbolic aspects of their identity: rites of passage, the tattoo meanings, the importance of the image etc. The article refers to the factors of popularity of these criminal groups among many young, poor and marginalised people in Central America.

Keywords: criminal gangs, rites of passage, tattoos, identity, subculture of violence

\section{Streszczenie}

\section{Znaczenie rytuałów inicjacyjnych i tatuaży w „maras” i „pandillas” Ame- ryki Środkowej}

Artykuł podejmuje wątek istniejących w regionie Ameryki Środkowej młodzieżowych gangów przestępczych (maras y pandillas) pod kątem symbolicznych determinantów określających mechanizmy ich funkcjonowania. Egzemplifikację zawartych w nim rozważań stanowią przede wszystkim grupy określane umownie jako La Mara Salvatrucha, działające w kilku państwach środkowoamerykańskich. Artykuł ukazuje te zbiorowości jako specyficzny rodzaj współczesnych „miejskich plemion” i subkultur, w których szczególną rolę odgrywają zwyczaje inicjacyjne i inne aspekty dystynktywne, takie jak określony wizerunek, kreowany m.in. za pomocą tatuaży, slangu, odzieży. Analiza tu zawarta zwraca uwagę na poszczególne wymiary tożsamościowe oraz identyfikacyjne osób należących do subkultur przestępczych tego typu, jak również na uwarunkowania endogenne, sprzyjające ich oddziaływaniu szczególnie na ludzi młodych i werbowaniu ich do szeregów tych organizacji.

Słowa kluczowe: gangi, przestępczość, rytuały wejścia, tatuaże, tożsamość, subkultura 